\section{Kaolin Clotting Time}

T. Stief

Institut für Laboratoriumsmedizin und Pathobiochemie,

Krankenhaus der Philipps-Universität, Marburg, Deutschland

\section{$\operatorname{Synonym(e)~KCT~}$}

Englischer Begriff kaolin clotting time

Definition Die Kaolin Clotting Time (KCT) ist ein sensitiver Test für Inhibitoren des intrinsischen Gerinnungswegs und wird seit Jahr 1978 zur Bestimmung von LupusAntikoagulans eingesetzt.

Beschreibung Die KCT ist eine modifizierte aktivierte partielle $>$ Thromboplastinzeit (APTT), wobei plättchenarmes Plasma (PPP) mit Kaolin als Oberflächenaktivator ohne Zusatz von Phospholipiden inkubiert wird. Die im PPP noch vorhandenen Phospholipide z.B. aus HDL/LDL-Partikeln genügen für die F10a/F2a Generierung (ähnlich wie beim recalcified coagulation activity assay $=$ RECA). Zur Bestätigung eines Lupus-Antikoagulans wird ein Plasmatauschver- such mit Normalplasma angesetzt und dann die KCT bestimmt.

$$
\text { Rosner }-\operatorname{Index}(R I)=\frac{[K C T(\text { Mix })-K C T(\text { Normalplasma })]}{K C T(\text { Patient })}
$$

KCT (Mix): KCT-Bestimmung mit 1 + 1-Mischung von frischem Patienten- und Normalplasma ( $<2 \mathrm{~h}$ Raumtemperatur alt)

KCT (Patient): KCT-Bestimmung mit dem Patientenplasma

Bei Anwesenheit von Lupus-Antikoagulans: KCT $(\operatorname{mix}) \approx \mathrm{KCT}$ (patient)

Bei Abwesenheit von Lupus-Antikoagulans: KCT $(\operatorname{mix}) \approx \mathrm{KCT}$ (normal)

Normalbereich Rosner Index $<0.15$ (entspricht $<15 \%$ )

\section{Literatur}

Rosner R, Pauzner R, Lusky A (1987) Detection and quantitative evaluation of lupus antikoagulant activity. Thromb Haemost 57:144-147 Stief TW (2009) 32-glycoprotein-1 antibodies trigger thrombin generation. Hemost Lab 2:223-246 